\title{
CERVICAL LYMPHANGIOMA IN ADULT- A CASE REPORT
}

\author{
Pradeep Balineni ${ }^{1}$, Samuel Dev Merlin², Sandeep Pathivada ${ }^{3}$,Prasanna Manickam ${ }^{4}$, Shruthi Kamal ${ }^{5}$
}

1 Postgraduate Student, Department of General Surgery, Saveetha Medical College, Chennai, Tamilnadu, India. 2Postgraduate Student, Department of General Surgery, Saveetha Medical College, Chennai, Tamilnadu, India. 3Postgraduate Student, Department of General Surgery, Saveetha Medical College, Chennai, Tamilnadu, India. ${ }^{4}$ Postgraduate Student, Department of General Surgery, Saveetha Medical College, Chennai, Tamilnadu, India. 5 Professor and HOD, Department of General Surgery, Saveetha Medical College, Chennai, Tamilnadu, India.

HOW TO CITE THIS ARTICLE: Balineni P, Merlin SD, Pathivada S, et al. Cervical lymphangioma in adult- a case report. J. Evolution Med. Dent. Sci. 2019;8(12): 951-952, DOI: 10.14260/jemds/2019/210

\section{PRESENTATION OF CASE}

A 28-years-old female patient presented with complaints of swelling on the left side of neck of 2 months duration. The swelling was insidious in onset and progressive in nature. There was no history of fever, trauma or discharge from swelling. Clinical examination revealed a swelling that was soft, cystic, compressible, non-tender, and mobile. Transillumination test was positive (Fig. 1). On MRI, it showed a cystic swelling with no connection with any major vessels or the thoracic duct (Fig. 2). Patient was taken up for complete surgical excision. Intra operatively a turbid swelling with a thin wall was seen with a feeding vessel from the transverse cervical artery which was ligated and cut (Fig. 3, 4). Post operatively patient had no complications of seroma formation, haemorrhage or haematoma. Post-operative biopsy showed single layer of endothelium lined by flat fibrocollagenous wall suggestive of lymphangioma.

\section{CLINICAL DIAGNOSIS}

Lymphangioma

\section{DIFFERENTIAL DIAGNOSIS}

1. Haemangioma

2. Lipoma

\section{DISCUSSION}

Cervical lymphangiomas are rare benign, congenital, cystic lesions, commonly seen in the head and neck regions. They are most common in the posterior triangle of neck (97\%) followed by sub-mandibular region (20\%), and $5 \%$ in rare site like abdomen, axilla, shoulder, chest wall, parotid region. ${ }^{1}$ Incidence of these lesions are 1.2-2.8\% per 1000 new born, with no sexual predilection. $1,2,3$ They are due to the abnormal development of lymphatic tissues in childhood 1,4 . The possible theories are developing lymphatic tissue not getting properly anastomosed, lymphatic tissue not getting anastomosed with the veins and arteries, lymphatic tissues getting harvested in wrong places in childhood.2,5 The y are mostly seen children of age 3-5 years and rarely in adults 6 , with only a fewer than 100 cases reported in English literature. ${ }^{3}$

'Financial or Other Competing Interest': None.

Submission 07-02-2019, Peer Review 12-03-2019,

Acceptance 19-03-2019, Published 25-03-2019.

Corresponding Author:

Pradeep Balineni,

Plot No. 112, Revenu Colony,

Near SSN Degree College, MM Donka, Ongole-523002,

Prakasam Dist., Andhra Pradesh, India.

E-mail:pradeep052191@gmail.com

DOI: $10.14260 /$ jemds $/ 2019 / 210$
They are divided into 3 types capillary (Microcytic), cavernous (Macrocytic), cystic (Cystic Hygroma). Cystic hygromas consist of $90 \%$ of lymphangiomas. ${ }^{3}$ The term cystic hygroma was first used in 1843 by Wernher, cystic is for the consistency and hygroma in Greek means 'moist tumour'. Bill and Summer hypothesized in 1965 as cystic hygroma and lymphangioma to be two different disease. ${ }^{1}$ Capillary type is believed to be occurring soft tissues like sub cutaneous whereas cavernous in dense tissues like tongue.

They most commonly present as a large, soft, cystic, compressible, non-tender and transillumination positive. ${ }^{7}$ In adults they would be silently present from childhood but increase in size due factors like upper respiratory tract infection or incidental trauma.2,3 They can occasionally cause symptoms due to compression on organs in rare sites 5 . These swellings may aggressively infiltrate nearby tissues or spontaneously regress in size (15\% of cases). ${ }^{2}$ Indications for surgery in cases of adults would be due to disfigurement, large size, leak due to rupture, recurrent infection. ${ }^{2}$ Disfigurement is the indication of surgery in this case. Main complications would be haemorrhage, infection and rupture. ${ }^{5}$ They are generally associated with trisomies of $13,18,21$, turners syndrome, Noonan syndrome. ${ }^{2}$ Ultrasound, CT, MRI can be done for the cases, ultrasound shows the nature of the lesion, CT and MRI would show the relation of lesion to the nearby structures, whereas MRI would be more sensitive. MRI is the investigation we have done in this case. On ultrasound it is seen as hypoechoic lesion with trabecula, on CT they are hypodense and multilocular, on ${ }^{2}$ MRI T1 weighed it would be hypointense to muscle and on T2 weighed it would be isointense to cerbrospinal fluid and hyperintense to fat. Prenatal ultrasound would help to diagnose the case in utero. Microscopic picture would be dilated lymphatic channels with one (or) two endothelial layers with or without adventitial layer. ${ }^{1}$

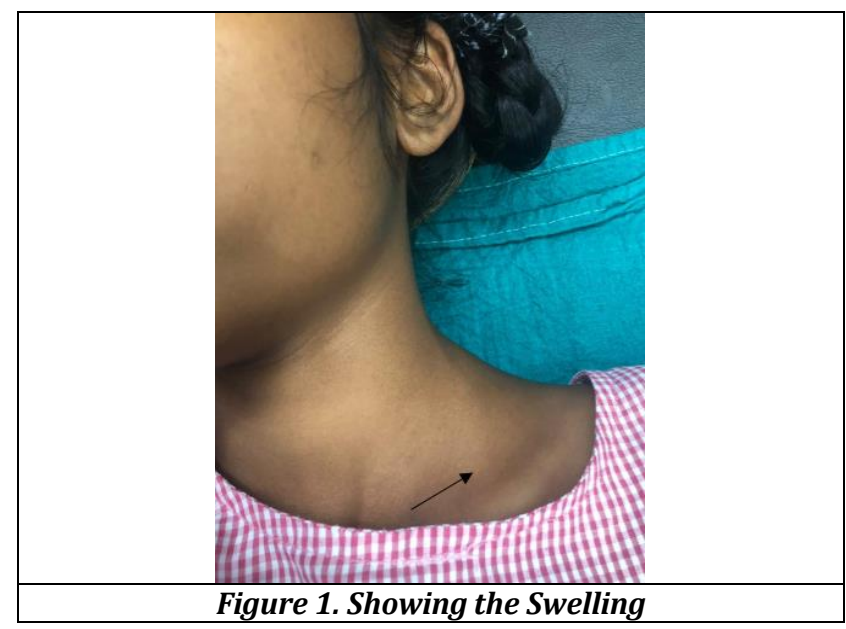



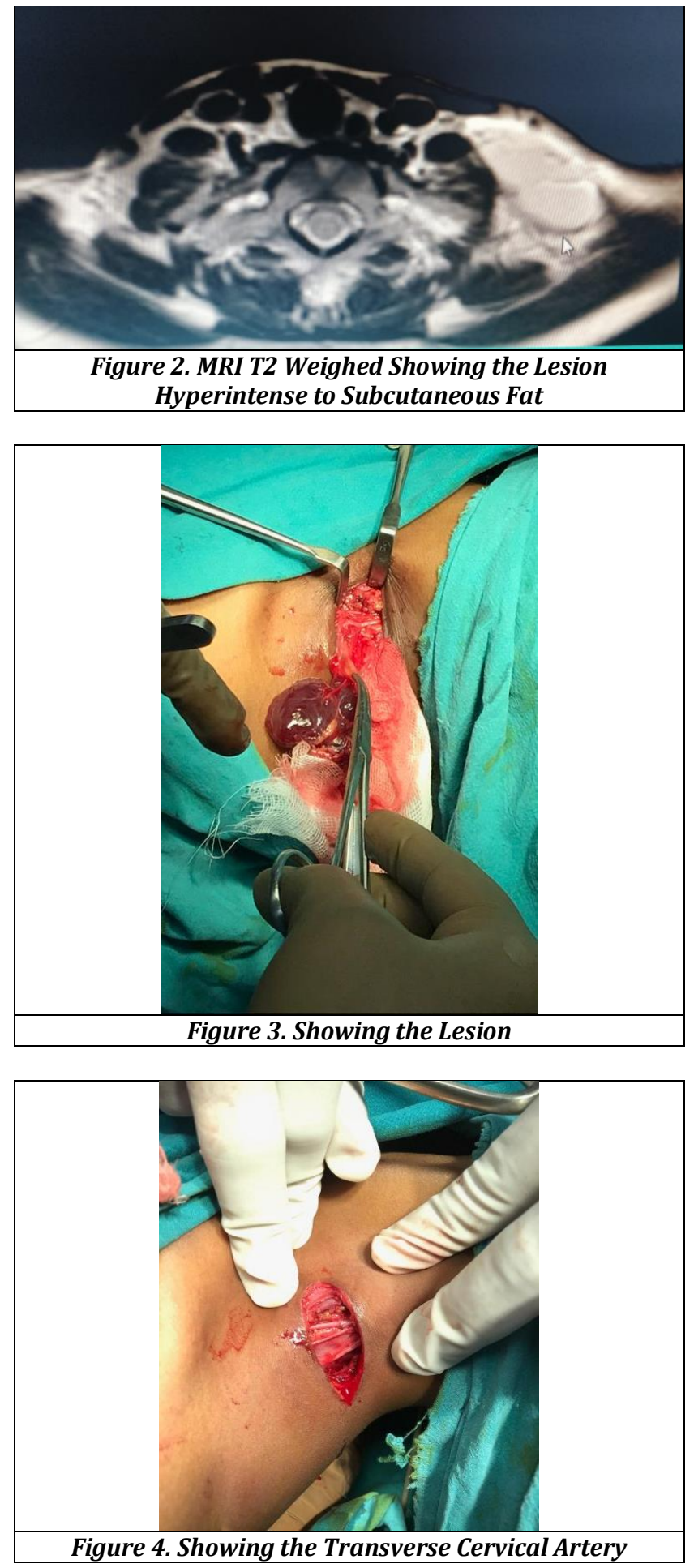

\section{DISCUSSION OF MANAGEMENT}

Complete surgical resection is the treatment of choice with $81 \%$ of success rate. ${ }^{3}$ Recurrence is seen about $10-27 \%$ post complete excision and $50-100 \%$ in partial resection. Outcome of surgery can be predicted as cervicofacial lesions have more success rate than any other parts and infrahyoid lesions have more success rate than suprahyoid. ${ }^{1}$ Age has no role towards outcome of the surgery. Postoperative complications generally would be infection, haemorrhage, hematoma formation, seroma and injury to the neuro-vascular bundle. The lymphatics nearby to the thoracic duct are to be individually ligated ${ }^{5}$ and cut so as to decrease the post op seroma collection rates. We had experienced no complications in this case. Other non- surgical techniques would be aspiration, radiotherapy, sclerotherapy for unresectable and recurrent cases. ${ }^{1,8}$ General sclerotherapy agents used are sodium morrhuate, dextrose, tetracycline, doxycycline, bleomycin, OK-432 (has low perilesional fibrosis). ${ }^{9}$ Okazaki et.al ${ }^{1}$ recommended use of only OK-432 sclerotherapy for single cystic and macrocytic type of lesions. ${ }^{2,5}$

\section{FINAL DIAGNOSIS}

Left Side Cervical Lymphangioma

\section{REFERENCES}

[1] Basurto-Kuba P, Otto E, Hurtado-Lopez M, et al. Linfangioma de cuello en el adulto. Reporte de 2 casos. Cirugía y Cirujanos 2016;84(4):313-7.

[2] Grasso DL, Pelizzo G, Zocconi E, et al. Lymphangiomas of the head and neck in children. ACTA Otorhinolaryngologica Italica 2008;28(1):17-20.

[3] Jaiswal AA, Garg AK, Ravindranath $M$, et al. A huge congenital cervical lymphangioma - case report with review of literature. Egyptian Journal of Ear, Nose, Throat and Allied Sciences 2015;16(3):283-90.

[4] Rodríguez PM, Navarro JR. Higroma quístico. An Orl Mex 2009;54(1):28-31.

[5] Kandakure VT, Thakur GV, Thote AR, et al. Cervical lymphangioma in adult. Int $\mathrm{J}$ Otorhinology Clin 2012;4(3):147-50.

[6] Naidu SI, McCalla MR. Lymphatic malformations of the head and neck in adults: a case report and review of the literature. Ann Otol Rhinol Laryngol 2004;113(3 Pt 1):218-22.

[7] Mirza B, Ijaz L, Saleem M, et al. Cystic hygroma: an overview. J Cutan Aesthet Surg 2010;3(3):139-44.

[8] Schuster T, Grantzow R, Nicolai T. Lymphangioma colli - a new classification contributing to prognosis. Eur J Pediatr Surg 2003;13(2):97-102.

[9] Sichel JY, Udassin R, Gozal D, et al. OK-432 therapy for cervical lymphangioma. Laryngoscope 2004;114(10):1805-9. 